\title{
EL OBISPO, MAESTRO DE LA FE Y HERALDO DE LA PALABRA
}

DOI: https://doi.org/10.52039/seminarios.v50i171.768

Autor: Mons. José Delicado Baeza. Arzobispo emérito de Valladolid.

Al hilo del cap.III de Pastores gregis, D. José va exponiendo la realidad del Obispo como maestro de la fe, haciéndola presente en su vida y heraldo de la Palabra, del Evangelio que tiene como centro a Cristo crucificado, y que como oyente atento comunica lo que vive en su interior. 
Deber de todos los miembros de la Iglesia, pero, en virtud de la vocación y ordenación episcopal, especialmente de los obispos, sucesores de los apóstoles. La expresión Reino de Dios aparece más de cien veces en el Nuevo Testamento, la mayor parte en los labios de Jesús, que, al comienzo de su ministerio, marcha a Galilea a proclamar el Evangelio de Dios diciendo: "Se ha cumplido el plazo, está cerca el Reino de Dios: convertíos y creed el Evangelio" (Mc 1, 14).

Los Apóstoles, siguiendo el mandato de Jesús resucitado, proclaman el Evangelio, insistiendo, como tema central del mismo, en Cristo muerto y resucitado, con lo cual parecen introducir un nuevo contenido del reino en este desplazamiento terminológico, pero en realidad es el mismo, porque Cristo en persona es el Reino de Dios para los hombres. La promesa y el futuro ya es presencia en Él como salvador que no abandona jamás tras su resurrección. El Reino de Dios -lo dijo Jesús- se encuentra en Él, aunque de tal modo que todavía puede pasar inadvertido: "Si yo arrojo los demonios por el dedo de Dios, es que el Reino de Dios ha llegado a vosotros" (Lc 11, 20). Jesús es el mismo reino, la "autobasileia", escribió Orígenes.

Por eso, cuando los Apóstoles, el día de Pentecostés, anuncian a Jesús muerto y resucitado, es decir, el "misterio pascual", nueva expresión del Reino de Dios como Buena Noticia, las palabras llegan al fondo del corazón de los oyentes, que preguntan a Pedro y a los demás apóstoles qué tienen que hacer para salvarse. La respuesta es la misma: tienen que arrepentirse, pero con esta adición: bautizarse cada uno en nombre de Jesucristo para obtener el perdón de los pecados (cf. Hech 2, 31-32).

La actividad evangelizadora del obispo está orientada a conducir a los hombres a la fe y a la vida cristiana, como una manifestación "preeminente de su paternidad". San Pablo no duda en decir que se trata de una nueva generación por la predicación del Evangelio (cf. 1 Co 4, 15). "Precisamente por este dinamismo generador de vida nueva según el Espíritu, el ministerio episcopal se manifiesta en el mundo como un signo de esperanza para los pueblos y para cada persona". Jesús hace presente el reino en su persona y mediante la irradiación del Espíritu Santo, gracias a su actividad "pneumática", que llega a todos los hombres de diversas maneras, pero especialmente mediante la predicación evangélica (cf. Rm 10, 13-15). El obispo es el predicador de la palabra evangélica con esta finalidad generadora, 
como ministro de la verdad, misión que ha de cumplir con fortaleza y confianza.

El ministerio del obispo se relaciona con cada una de las personas divinas. La teología occidental vincula especialmente al obispo con la persona del Hijo. Este es el primer plano que aparece en los documentos conciliares: en los obispos, Cristo está presente entre los fieles (LG 21). Representa a Cristo, el Señor; es, por formar parte de la sucesión apostólica, su enviado. La teología oriental subraya preferentemente sus relaciones con el Padre. El Padre es la fuente de la vida. Para San Ignacio de Antioquia "el obispo es la imagen del Padre", fórmula repetida en numerosos textos del Oriente. La generación en Cristo, por el Evangelio, según la citada alusión paulina, tiene en el trasfondo esta imagen paterna. Ambos aspectos son inseparables y complementarios, la referencia al Padre y al Hijo, suponiendo la misión vivificante y animadora del Espíritu Santo. Su envío significa la garantía perdurable de la función apostólica, que, en el Espíritu, este ministerio episcopal se hace instrumento de Cristo resucitado. Gracias al don del Espíritu Santo, el ministerio episcopal está llamado a ser garante de la verdad evangélica y del servicio a la comunión de la Iglesia, "como muchedumbre reunida por la unidad del Padre y del Hijo y del Espíritu Santo", según nos recuerda el Vaticano II (LG 21).

Esta vinculación trinitaria del obispo le obliga a actitudes profundas: Si ha de ser en su paternidad la imagen del Padre; en su envío y presencia, la representación del Hijo, y en su propia vida de creyente, para poder conducir a los hombres a la fe y a la vida cristiana, un signo del Espíritu Santo que le asiste en esta misión, la fuerza que necesita para realizarla tiene este referente trinitario en su propia vida teologal, que ha de manifestar, como "primer predicador del Evangelio con la palabra y con el testimonio de vida". Ha de ser reconocida su autoridad-poder por parte de la comunidad eclesial a la que sirve; pero él mismo ha de tener siempre ante sus propios ojos su calidad de testigo del Resucitado, sin haberle visto como los primeros apóstoles, pero a la manera de los verdaderos creyentes (cf. Heb 11, 27).

\section{Cristo, el corazón del Evangelio y del hombre}

El centro vivo del anuncio del Evangelio es Cristo crucificado y resucitado para la salvación de todos. Jesucristo es el corazón del 
Evangelio y de toda la predicación, fuente de la que dimanan las verdades de fe, la razón cumplida de la esperanza inquebrantable y de la inagotable corriente de amor para la solidaridad humana en todas las circunstancias de la Historia. Este es el plan que Dios había proyectado realizar por Cristo, cuando llegase el momento culminante: recapitular en Él todas las cosas del cielo y de la tierra ( cf. Ef 1, 10). Por eso es el programa obligado de todo el mensaje evangélico para la salvación del mundo.

La "protología", es decir, el tratado de la creación originaria, está en función de la "escatología", el tratado de la plenitud final a la que se dirige la humanidad y el mundo en curso, y todo ello mediado por la "cristología", es decir, el Verbo encarnado y su obra salvadora, como un hombre de tantos. Pero habiéndose rebajado de tal manera, que en su servicio no rehusó la muerte de cruz, y por haberse entregado a ella para salvarnos a todos, se muestra glorificado por el Padre en su resurrección como Señor único y universal (cf. Flp 2, 6-11). Por ello, hay que intuir a Cristo en su preexistencia humana como Verbo eterno, y, llegado el momento de su encarnación, en su "proexistencia" para la salvación de todos, como hermano, siervo entregado y ahora glorioso, a quien hay que acatar con gozoso estupor, y seguir y confesar con fidelidad inquebrantable, porque es el Señor. El punto ineludible es la Pascua de Jesús, cuyo anuncio profético no sólo nos sitúa en el más allá de nuestra propia vida temporal, sino que nos incita a pensar en la eternidad que precede al tiempo y en la eternidad que supera al tiempo y no acaba nunca, pero que ya está presente en el tiempo y en la cual estamos comprendidos todos, porque "en Jesucristo, Verbo encarnado, el tiempo llega a ser una dimensión de Dios, que en sí mismo es eterno", dice la carta apostólica Tertio millennio adveniente. Cristo no se limita a hablar "en nombre de Dios" como los demás profetas, sino que es Dios mismo quien nos habla en su Verbo hecho carne. Este es "el punto esencial por el que el cristianismo se diferencia de las otras religiones, en las que desde el principio se ha expresado la búsqueda de Dios por parte del hombre. El cristianismo comienza con la encarnación del Verbo. Aquí no es sólo el hombre quien busca a Dios, sino que es Dios quien viene en Persona a hablar de sí al hombre y mostrarle el camino por el cual es posible alcanzarlo" (TMA 6).

Por eso, en la predicación evangélica hay que mostrar el rostro de Cristo, para que pueda ser contemplado por el hombre de hoy. La con- 
templación del rostro de Cristo, escribe el Papa en la otra carta apostólica, Novo millennio ineunte, hay que buscarla en lo que de Él dice la Sagrada Escritura, que, "desde el principio hasta el final, está impregnada de este misterio, señalado oscuramente en el Antiguo Testamento y revelado plenamente en el Nuevo, hasta el punto que San Jerónimo afirma con vigor: 'Ignorar las Escrituras es ignorar a Cristo mismo'. Pero sobre todo en los Evangelios, que, aunque no pretenden ser una biografía completa de Jesús según los cánones de la ciencia histórica moderna, 'sin embargo, de ellos emerge el rostro del Nazareno con un fundamento histórico seguro'" (NMI 17).

La revelación que Cristo hace de su propia identidad personal en relación con el Padre, está implicada en el misterio de su ser: como la Palabra se ocultó en su humanidad, así sus palabras sólo tuvieron las manifestaciones progresivas que esta humanidad en sus circunstancias concretas le permitían cuando predicaba e incluso cuando oraba y hacía los signos del Reino. El Padre, sin embargo, le exaltó de tal manera que la Palabra pasó del ocultamiento de la humillación a la claridad de la glorificación, por lo que la primitiva comunidad le reconoció en seguida como Señor, Mesías e Hijo de Dios, títulos que aparecen con toda evidencia en los Evangelios y en el resto del Nuevo Testamento. Jesús, en su persona y en su misión, implica un nuevo y definitivo actuar de Dios, y Él tenía conciencia de todo ello y de que había sido enviado, no para hacer un mundo mejor simplemente, sino un mundo nuevo, una "nueva creación".

Por eso la contemplación de Jesús como el Cristo y el Unigénito del Padre es una actitud fundamental de los verdaderos creyentes de todos los tiempos, puesto que se acreditan como cristianos en función de esta fe. La mirada puede dirigirse hacia arriba para contemplar al Verbo encarnándose en un movimiento descendente -"escatología de arriba"-, o puede iniciarse en Jesús, verdadero hombre en todo excepto en el pecado, para intuir su 'yo' profundo, es decir, la persona del Hijo de Dios: "cristología de abajo". Hay que unir las dos perspectivas, aunque sea en momentos sucesivos, para evitar el riesgo, que a veces se muestra recidivo a lo largo de la historia, de la "vivisección" de Cristo, bien por destacar su divinidad marginando su verdadera realidad humana, o al revés. Y todo esto no es inocente, porque una cristología parcial proyecta la correspondiente concepción eclesiológica, para terminar dictando lo que tienen que ser o hacer los cristianos en el mundo, 
con el peligro también de caer en un programa ideologizado. Pero el Espíritu Santo lleva a todo creyente humilde y sincero a la "verdad completa", que se encuentra en la comunidad eclesial y a dar fiel testimonio de Jesús. Esta es la gran responsabilidad de todo obispo al servicio de la Iglesia en su ministerio de evangelización.

\section{El Obispo, oyente y custodio de la Palabra}

"La misión de enseñar propia de los obispos consiste en conservar santamente y anunciar con audacia la fe" (PG 28). El gesto simbólico de depositar el Evangeliario en la cabeza del obispo en su ordenación sacramental significa que ha de acogerlo en su mente y también en su corazón, para vivirlo con creciente fidelidad y anunciarlo con inquebrantable fortaleza en su testimonio personal. Para ello, antes que predicador ha de ser oyente de la Palabra.

Ser oyente de la palabra de Dios significa, en primer lugar, la aceptación del mensaje que encierra esa Palabra; pero inmediatamente después incluye la sumisión de todo el creyente a la gracia transformadora de Cristo. Las dos cosas. El contenido intelectual de esta palabra es la auto-entrega de Dios Padre por Cristo en el Espíritu Santo que anima a la Iglesia, es decir, la actividad salvadora de Dios en la historia de los hombres para atraerlos a su vida. Comporta, pues, una consecuente entrega del creyente a Dios en todo aquello que reclama la palabra de Dios para acoger la alianza que nos ofrece. El Verbo encarnado es a la vez Palabra de verdad y de vida. Decir que "sî" con el entendimiento al Verbo encarnado y "no" con el corazón es el riesgo de toda libertad humana; el sí pleno hay que dárselo no sólo como Maestro, sino también como Salvador. Por eso la fe, en este compromiso personal, ha de ser la disposición dinámica de una permanente conversión.

El objeto de la fe, como decíamos, se resume en la persona de Cristo; el proceso es seguirle a Él, hacerse discípulo suyo. La finalidad es adherirse a su persona, poseer su vida, dejar que Cristo lo sea todo en el creyente. Esta adhesión personal no consiste sólo en creer "a" Cristo en su enseñanza, sino creer "en" Él, acogerle en lo profundo de uno mismo sin reservas, dejarse enseñar por su Espíritu, seguirle con fidelidad tras sus huellas, dejar que Cristo more en el creyente de manera que éste permanezca en Él. Así es como se van interiorizando 
sus palabras, sus criterios y hasta sus sentimientos en comunión con Él: "Tened los mismos sentimientos de Cristo", escribió San Pablo (Flp 2, 5). En esta experiencia se capacita el creyente para ser su testigo y mensajero del Evangelio. Los Apóstoles, en su predicación evangelizadora, no eran doctrinarios o propagandistas de un sistema religioso. Eran primariamente heraldos de la Buena Noticia, testigos de Alguien: "Nosotros no nos predicamos a nosotros mismos, predicamos que Cristo es Señor y nosotros siervos vuestros en Jesús" (2 Co 4, 5). Pero esa verdad nuclear, de la que se derivan todas las que comprende el Credo de la fe cristiana, ha tenido su necesario desarrollo, tanto en la Sagrada Escritura de ambos Testamentos como en la Tradición cristiana, formando el único depósito de la Revelación divina.

Por eso dice este apartado de la exhortación: "Así, la Palabra transmitida, la Tradición, se ha hecho cada vez más conscientemente Palabra de vida y, entre tanto, la tarea de anunciarla y custodiarla se ha realizado progresivamente, bajo la guía y la asistencia del Espíritu de Verdad, como una transmisión incesante de todo lo que la Iglesia es y de todo lo que ella cree. Esta Tradición, que tiene su origen en los Apóstoles, progresa en la vida de la Iglesia, como ha enseñado el concilio Vaticano II. De modo similar crece y se desarrolla la comprensión de las cosas y las palabras transmitidas, de manera que al creer, practicar y profesar la fe transmitida, se establece una maravillosa concordia entre obispos y fieles". Asistidos por el Espíritu Santo, brota el "sentido de la fe" de todo el pueblo de Dios, que no puede equivocarse cuando "desde los obispos hasta el último de los laicos cristianos muestran estar totalmente de acuerdo en cuestiones de fe y de moral" (LG 12).

El obispo, condiscípulo con los demás creyentes en la misma escuela de la Iglesia, como diría San Agustín, respecto al único Maestro, que es Cristo, tiene una responsabilidad peculiar desde su cátedra docente: "conservar santamente y anunciar con audacia la fe". Pero en este deber misionero de la evangelización, el ministerio apostólico ha de tener en cuenta el destino de salvación para todos los hombres. Por eso escribió Pablo VI en su encíclica Ecclesiam suam: "No es suficiente una actitud fielmente conservadora. Ciertamente, tendremos que guardar el tesoro de la verdad y de la gracia, legado a nosotros en herencia por la tradición cristiana; más aún: tendremos que defenderlo: 'Guarda el depósito', amonesta San Pablo (1 Tim 6, 20). Pero ni la guarda ni la defensa encierran todo el quehacer de la Iglesia respecto 
de los dones que posee. El deber congénito al patrimonio recibido de Cristo es la difusión, es el ofrecimiento, es el anuncio: 'Id, pues, y enseñad a todas las gentes' (Mt 28, 19) es el supremo mandato de Cristo a sus Apóstoles" (ES 63).

Para que el mensaje de salvación tenga aplicación real hay que escuchar el latido del corazón del hombre concreto e histórico en todo tiempo y lugar y, en el momento presente, el que brota de la globalización con todas sus consecuencias en relación con anchas capas humanas en que desaparecen los valores condicionantes para recibir el mensaje evangélico por oponerse a él.

La carta apostólica Novo millennio ineunte nos ofrece un panorama amplísimo de la pobreza con los problemas nuevos. El cristiano sincero debe contemplarlo, para vivir la fe en Cristo y transmitir fielmente el mensaje evangélico: "Se trata de continuar una tradición de la caridad que ya ha tenido muchísimas manifestaciones en los dos milenios pasados, pero que hoy quizá requiere mayor creatividad. Es la hora de una nueva 'imaginación de la caridad', que promueva no tanto y no sólo la eficacia de las ayudas prestadas, sino la capacidad de hacerse cercanos y solidarios con quien sufre, para que el gesto de ayuda sea sentido no como limosna humillante, sino como un compartir fraterno. Por eso tenemos que actuar de tal manera que los pobres, en cada comunidad cristiana, se sientan como en su casa. ¿No sería este estilo la más grande y eficaz presentación de la buena nueva del Reino?" (NMI 50). De este modo, el mensaje evangélico urge la vinculación de la mente y el corazón para poder ser acogido y difundido. Realmente Jesús manifiesta que ha venido a anunciar el Evangelio a los pobres; para esa misión ha recibido la unción del Espíritu (cf. Lc 4, 18). Juan Pablo II ha traducido prácticamente esta cristología para el siglo y el milenio que comenzamos. Después de narrar el pasaje de Mateo 25, 35-36, que contiene las mismas palabras de Jesús sobre su "identificación" con los pobres, añade: "Esta página no es una simple invitación a la caridad: es una página de cristología, que ilumina el misterio de Cristo. Sobre esta página, la Iglesia comprueba su fidelidad como Esposa de Cristo, no menos que sobre el ámbito de la ortodoxia" (NMI 49).

En la Iglesia, obispos y fieles son condiscípulos instruidos por el Espíritu que imparte su enseñanza interior de muchas maneras: en el corazón de cada uno, en las comunidades eclesiales, en las Iglesias particulares, en sus personas e instituciones, mediante lenguajes conoci- 
dos y otros diversos y nuevos, suscitando diferentes formas de carismas y servicios. Por todo ello, el obispo, para ser fiel a su misión evangelizadora, ha de facilitar los encuentros entre las personas, comunidades e instituciones, vivir él mismo esa presencia interpersonal y crear ese ámbito de comunión para la misión, que garantiza en la práctica el mensaje de Cristo en su ambivalencia de ortodoxia y ortopraxis, porque la Palabra de Dios lo reclama así.

\section{El servicio auténtico y autorizado de la Palabra}

Por la ordenación episcopal, el obispo ha recibido la misión fundamental, como auténtico maestro, de anunciar autorizadamente la Palabra, está revestido de la autoridad misma de Cristo, y su enseñanza, en comunión con el Romano Pontífice, merece la acogida y el respeto de los cristianos. "Los fieles necesitan la palabra de su obispo; necesitan confirmar y purificar su fe" (PG 29). Este servicio que realiza en su Iglesia adquiere diversas formas, según la situación en que se encuentran los destinatarios: el "kerigma" para la evangelización, que también puede ser gradual y progresiva, desde la llamada a la fe inicial, pasando por su reanimación, cuando está adormecida por la indiferencia o la ignorancia religiosa; la catequesis, que desarrolla los contenidos de la fe para la maduración de la vida cristiana, función en la que el obispo es el catequista por excelencia; y las diversas formas de iniciación y animación de las celebraciones litúrgicas, especialmente la de la Eucaristía, que, con ser sacramentales, están condicionadas por el ministerio de la palabra, sin cuyo servicio los sacramentos difícilmente serían signos eficaces de fe.

Para ejercer esa función de la dirección de la catequesis, el obispo cuenta con las directrices que le brinda la Iglesia, como el Catecismo de la Iglesia Católica, la exhortación apostólica Catechesis tradendae, directorios para formar catequistas, etc., que há de procurar adaptar, cuidando de las mismas personas, con orientaciones precisas, cursos de formación e intervenciones directas, suscitando un gran sentido vocacional por la catequesis como función básica y especialmente necesaria en nuestro tiempo, según ministerios y carismas, comprometiendo a sacerdotes y diáconos, personas consagradas, padres de familia, agentes pastorales, catequistas a los que se confía este ministerio, 
profesores de religión en las escuelas estatales y de iniciativa social, profesores de teología y de ciencias eclesiásticas, etc. "El obispo cuidará la formación inicial y permanente de todos ellos".

En estos trabajos y los que afectan a su misión evangelizadora, ha de contar con el servicio y colaboración de los teólogos, "a los que corresponde profundizar con métodos apropiados la insondable riqueza del misterio de Cristo". El magisterio episcopal está al servicio de la proclamación auténtica del mensaje cristiano. Los teólogos, de algún modo, ejercen una función mediadora entre este magisterio y la comunidad eclesial. De ahí la necesidad del diálogo vinculado a la Palabra de Dios. "El Magisterio no está por encima de la Palabra de Dios, sino a su servicio, para enseñar puramente los transmitido, pues (...) lo escucha devotamente, lo conserva celosamente y lo expone fielmente, y todo lo que propone para ser creído como revelado por Dios lo saca de este único depósito de la fe", enseña el Vaticano II (DV 10). Y a su vez "la de su capacidad y vocación científica al servicio del mensaje evangélico, que ha de estar acompañada de la experiencia de la propia fe vivida en comunión eclesial, pero en la libertad teología se apoya en la Palabra de Dios escrita, lo mismo que en la Santa Tradición como sobre fundamento permanente; allí encuentra la garantía más sólida de su fuerza y principio de juventud siempre renovada, mientras que escruta a la luz de la fe toda la verdad encerrada en el misterio de Cristo" (DV 24).

Los dos tienen la obligación de atender al "sentido de la fe" en la Iglesia de siempre. Así la palabra de Dios se extiende a todos los tiempos en este "sentido común de la fe", que, asistido por el Espíritu Santo, hace que el pueblo de Dios en su totalidad no pueda equivocarse si se da esa "singular concordia entre pastores y fieles en el mantenimiento, la práctica y la confesión de la fe transmitida" (DV 10). La infalibilidad descansa en la colectividad de los fieles con el colegio de los obispos en comunión con el Sucesor de Pedro (LG 12). Por eso, en la práctica de esa responsabilidad compartida, se ha de contar con la colaboración de los teólogos, sin la cual no habría avances en el mensaje evangelizador en las diversas circunstancias históricas en que se encuentran los destinatarios, lo cual reclama investigación y reflexión, interpretación y orientaciones prácticas del mensaje revelado. El Magisterio episcopal tiene esa autoridad y potestad sagrada derivada de la ordenación sacramental, que es la capacidad de enseñar, carismática y jurídica a la vez, como derecho y deber participados de la autoridad 
y encomienda de Cristo. A los teólogos les asiste también una cierta autoridad derivada de su propia función investigadora, científica y también docente que les compete en la Iglesia.

En todo esto hay que tener en cuenta que el depósito revelado contiene también el conjunto de valores morales que expresan la voluntad de Dios en sus mandamientos, para la libertad verdadera y la salvación de la persona, los cuales tienen una validez universal. "Esto vale especialmente por lo que se refiere a la vida humana, que se ha de proteger desde la concepción hasta su término con la muerte natural, la libertad de las personas y de las naciones, la justicia social y las estructuras para ponerla en práctica" (PG 29). La carta apostólica Tertio millennio adveniente nos recuerda las dificultades que actualmente existen en la transmisión de estos valores, por la indiferencia religiosa, la ignorancia y la confusión, que debilitan la misma vida cristiana: "No se puede negar que la vida espiritual atraviesa en muchos cristianos un momento de incertidumbre que afecta no sólo a la vida moral, sino incluso a la oración y a la misma rectitud teologal de la fe" (TMA 36), provocado por desorientaciones teológicas y por la crisis de desobediencia al Magisterio de la Iglesia.

Ante este panorama, hay que tener en cuenta la evolución del mismo pensamiento teológico de la Iglesia, que en tiempos pasados se enseñaba en diversas escuelas eclesiales, siempre toleradas si no se oponían a los contenidos dogmáticos. Esta diversidad de escuelas y de tendencias teológicas descansaba en presupuestos filosóficos y antropológicos, lingüísticos y científicos, ámbitos vitales, etc., compartidos por todos. Ahora el pluralismo de pensamientos y concepciones, por el resurgimiento en gran parte de los avances de las ciencias en todos los campos, produce el fenómeno de la especialización del saber en análisis y divisiones constantes, que pueden considerarse un resultado inevitable del progreso, pero que no carecen de connotaciones negativas para la verdad estable con pretensiones de universalidad. He aquí el relativismo sobre las "verdades" no inmediata o positivamente comprobables como realidades experimentables. De ahí surge la necesidad "científica" de introducir en la reflexión teológica, para fundamentar la fe, la aceptación de un nuevo pluralismo que ya no goza de los mismos valores comunes en los presupuestos metodológicos aludidos de otro tiempo, que ayudaban a confrontar las tendencias y los debates ante un mismo horizonte de convergencia en unas conclusiones de fe garantizada y segura. Los mis- 
mos teólogos, ante este panorama de prolífica e inevitable especialización, no se sienten capaces ahora como en otros tiempos de abarcarlo todo, sino más bien, como confiesa el mismo K. Rahner, como personas de pensamiento rudo o elemental, aun en los sectores de la teología que han cultivado muchos años. Otros llegan a decir que se está dando "el paso del modelo dogmático al hermenéutico".

Todo esto puede confundir el testimonio del mensaje evangélico ante el pueblo en interminables y sutiles razonamientos sobre teorías del lenguaje, de los géneros literarios, antropológicos y culturales, lícitos e inevitables en los ámbitos correspondientes del saber escriturístico y teológico, pero que se han de administrar debidamente teniendo en cuenta posibles destinatarios y hasta preguntándose los que ejercen esa loable labor investigadora, si también lo hacen desde la fe, no vaya a ser que se ofrezcan unos resultados desmitificadores que difuminen de tal manera el rostro de Cristo y su palabra salvadora en abstracciones, que no tengan nada que ver con la vida de fe, aunque parezcan eruditos y sabios. Con un Dios reducido a la abstracción y a la duda doctrinal es imposible que se pueda comunicar personalmente el espíritu humano, que necesita un Tú vivo, justamente el que nos revela Cristo con su palabra y su vida.

Por eso hay que tener en cuenta los dos principios que nos recuerda el Papa Juan Pablo II en su encíclica Fides et ratio: "Creo para entender", principio que se apoya en la Sagrada Escritura y especialmente en el testimonio de los Apóstoles, porque la obediencia de la fe abre unas posibilidades insospechadas fuera de ese ámbito para la comprensión y hasta para la misma aceptación de la verdad revelada por parte de la razón, y el otro principio inmediatamente unido de una manera inseparable, porque el acto de fe no es una actitud absurda ante el misterio revelado, "entiendo para creer", y cuanto más se pueda entender, mejor. De ahí la necesidad de una formación permanente, incluso teológica en los mismos creyentes, no digamos en los ministros y catequistas del Evangelio. Si se invierten los principios, puede que se pase mucho tiempo deseando aprehender el "Misterio", por su naturaleza inabarcable por la sola razón, sin llegar nunca a aceptarlo con fe viva y gozosa, capaz de dar sentido al hombre.

Son las mismas vidrieras de la catedral vistas desde el interior o el exterior. El obispo y el teólogo tienen que contemplarlas desde dentro, incluso para explicarlas a los viandantes de la calle. La propia 
experiencia interior de la fe es lo que ayudará para hacer más vivo y convincente el anuncio del misterio, como quienes dan testimonio de la Palabra encarnada, es decir, de Alguien que trasciende las puras categorías racionales pero que es capaz de transformar al hombre, respondiendo a sus más profundos deseos de sentido y de salvación completa. Se trata de una luz y energía nuevas: la gracia. No hay que rehuir las cuestiones actuales que preocupan al hombre, pero en la fidelidad y la óptica de la revelación cristiana. Por eso advierte este apartado de la exhortación: "Cuando se vea oportuno, los obispos deben defender con firmeza la unidad y la integridad de la fe, juzgando con autoridad lo que está o no conforme con la Palabra de Dios" (PG 29).

\section{Ministerio episcopal e inculturación del Evangelio}

"La evangelización de la cultura y la inculturación del Evangelio forman parte de la nueva evangelización y, por tanto, son un cometido propio de la función episcopal" (PG 30), dice este nuevo apartado. Tal como está redactado puede dar a entender que se trata de dos afirmaciones distintas: evangelización de la cultura, que parece una acción descendente -del Evangelio a la cultura-, y la inculturación, que más bien sugiere un movimiento ascendente, es decir, de asimilación de la cultura por parte del Evangelio, porque según la explicación siguiente, tan conocida, de Juan Pablo II: "una fe que no se convierte en cultura, es una fe no acogida, no totalmente pensada, no fielmente vivida". En todo caso, este doble movimiento que se ofrece como un único ministerio de vida y salvación, obedece a la ley de la encarnación del Verbo, y se puede contemplar de las dos maneras: de arriba abajo o viceversa; pero aun aplicado a la respuesta del hombre ante la revelación de Dios, la fe, aunque parezca una acción humana, ni siquiera ella, por ser teologal, es exclusiva propiedad humana, sino también gracia.

Sólo las personas son capaces de convertirse y tener fe, pero todas están condicionadas por la cultura envolvente, que surge del pensamiento y los valores en curso, de las ciencias y las artes, de las opiniones y creencias, de las tradiciones y pautas de comportamiento de los pueblos y sociedades en que viven los creyentes; de los modos de divertirse y buscar la felicidad, de los objetos en uso y de las fiestas, etc., con las influencias y corrientes, cauces y modas que transmiten y 
entretejen todas estas cosas en que vivimos y nos desenvolvemos y hasta somos atrapados, si nos descuidamos, los seres humanos. Pero asimismo, muchos de estos valores positivos pueden enriquecer a los creyentes cristianos, y hasta ellos mismos han de considerarse como fermento que ha de contribuir a levantar la masa del sentido y de los ideales de la sociedad, de los individuos que la componen y de la misma cultura, el tejido que la "conforma". De ahí la necesidad del diálogo evangelizador entre la fe y la cultura.

La evangelización de la cultura se hace en proceso de ósmosis enriquecedora o inculturación, pero de manera que el Evangelio en cuanto tal no se identifica con ninguna forma cultural concreta, sino que las trasciende a todas, purificándolas incluso desde su interior. Por eso el proceso de inculturación puede considerarse como el esfuerzo de la Iglesia por hacer penetrar el mensaje de Cristo en un determinado medio socio-cultural, contribuyendo a su crecimiento según sus valores propios, con tal de que sean conciliables con el Evangelio.

El concilio Vaticano II despertó una gran sensibilidad en la Iglesia para la comprensión de estas recíprocas relaciones. La fe cristiana impulsa al compromiso del servicio al hombre y de la promoción de la cultura, sobre todo si entran en juego la dignidad de la persona, los derechos humanos, la apertura a la trascendencia, el bien común de las sociedades, etc. Todos los fieles en general han de vivir en estrecha relación con los demás ciudadanos, esforzándose por comprender "su manera de pensar y sentir, cuya expresión es la cultura". Las nuevas ciencias y doctrinas y los más recientes descubrimientos han de ser tenidos en cuenta para que la respuesta y el servicio de la moral y la doctrina cristianas ayuden a interpretar esas diversas situaciones con sentido cristiano. Esta visión cultural, histórica y antropológica está al servicio del hombre, en un servicio evangelizador que no se puede separar de la cultura.

Este ha sido el cometido evangelizador de la Iglesia en todos los pueblos y en todos los tiempos, y debe seguir siéndolo en este milenio recién estrenado, purificando también comportamientos e intenciones, obedeciendo siempre al mandato misionero de Cristo, que afecta no sólo a los países de misión para la primera evangelización, sino de una manera nueva pero no menos apremiante a los de vieja cristiandad. "Cometido antiguo y siempre nuevo". Sobre todo en los países que, por ser desarrollados técnicamente, pueden creerse capaces de hacer vivir 
al hombre en la verdad definitiva y el sentido pleno de la vida, por lo cual se manifiesta en ellos una particular ruptura o distanciamiento entre la cultura y la fe religiosa.

Sin embargo, la nueva actitud de ciertos hombres de ciencia y de las otras disciplinas humanas, y a la vez de los creyentes, hace sentir cada vez más la necesidad de apertura para facilitar el diálogo. Fue, por ofrecer un ejemplo de cierta radicalización, Alfred Nobel quien escribió en su testamento que un progreso casi absoluto vendría de la mano de la ciencia: "Las conquistas de la investigación científica (...) infundirán en nosotros la esperanza de que poco a poco quedarán exterminados los microbios tanto del alma como del cuerpo, y que la única guerra en la que se comprometerá la humanidad será precisamente la guerra contra esos microbios".

Confianza desmesurada en la ciencia y sus aplicaciones por no contar con el corazón del hombre, que debe ser educado para utilizar bien este progreso. Vinieron las guerras cada vez más exterminadoras, el terrorismo cada vez más amplio y cruel, la contaminación de la naturaleza, las inmensas zonas de hambre y de muerte causadas por el egoísmo humano y la injusticia expansiva sobre los seres indefensos, las grandes y constantes corrientes migratorias que buscan la supervivencia, las dependencias de las drogas más diversas, incluso más devastadoras que la antigua esclavitud, y a pesar de todo el progreso, "nuevos" virus físi$\cos$, morales y sociales cuyas noticias alarmantes nos transmiten a diario los medios de comunicación social y a veces con publicidad y recomendación de los mismos, contaminan a las personas, el ámbito cultural en que éstas viven y hasta comprometen el futuro de las nuevas generaciones.

Podríamos decir que nos encontramos ante la gran desilusión, pero quizá sobrevenida por haber separado la ciencia del progreso moral, el cerebro del corazón humano. Sin embargo, el hombre necesita estas dos dimensiones que le son connaturales para vivir en plenitud. Esto deja un gran espacio para el diálogo entre la fe y la cultura, incluso la científica. La ciencia no es capaz de responder a la cuestión de sentido. El creyente busca la verdad y defiende la legitimidad de la ciencia abierta a la humanidad integral, que es tanto como decir al Absoluto o la trascendencia. La ciencia moderna se interroga a sí misma; pero es el hombre, científico o no, el que se preguntará siempre, con el deseo de captar lo absoluto y alcanzar así la sabiduría, por 
el propio sentido de su vida en este mundo y si existe algo más. Ahí, al filo de esta pregunta, aunque no es el único punto de apoyo sobre la realidad, sale la fe al encuentro. Para el creyente cristiano, la Palabra de Dios encarnada.

Por eso la Comisión Teológica Internacional (1988), reflexionando sobre la cultura moderna, aclara: "La inculturación del Evangelio en las sociedades modernas exigirá un esfuerzo metódico de investigación y de acción concertadas. Este esfuerzo supondrá en los responsables de la evangelización: una actitud de acogida y de discernimiento crítico, la capacidad de percibir los anhelos espirituales y las aspiraciones humanas de las nuevas culturas, la aptitud para el análisis cultural con vistas a un encuentro efectivo con el mundo moderno".

Quedan muchos territorios de misión en el mundo, muchos pueblos que evangelizar; pero la cuestión fuerte en nuestros países de vieja cristiandad es la de la evangelización de las culturas que plantea la sociedad con su progreso y sus nuevas formas de vida, con los medios de comunicación social y las mentalidades que genera, orientándolas hacia la indiferencia y el agnosticismo. Estos reflejos negativos de la cultura emergente se asemejan a veces a esos escapes de gases de las centrales nucleares, creadas para el progreso pero no exentas de estas amenazas, quizá como esos virus que hay que evitar, pero con una interpretación dialéctica de la frase de A. Nobel.

El Papa sugiere para estos trabajos la necesidad de la contribución de los teólogos, de expertos en las ciencias y en las artes, en el patrimonio cultural; la solícita atención y estima de los medios de comunicación social, la preparación para su uso en los agentes de pastoral, en los sacerdotes y en los seminarios, para que haya buenos predicadores y comunicadores, etc.

\section{Predicar con la palabra y el ejemplo}

"El ministerio del obispo, pregonero del Evangelio y custodio de la fe del pueblo de Dios, no quedaría completamente descrito si faltara una referencia al deber de la coherencia personal" (PG 31). Si no vive lo que enseña su magisterio de la fe como heraldo de la Palabra, parecería transmitir un mensaje contradictorio. El mensaje del Evangelio, que el obispo ha de comunicar con una autoridad ejercida en nombre 
de Cristo, compromete a la totalidad de su persona, no sólo a gestos más o menos periféricos de la misma.

Por eso, en esta función, que se podría parecer a la de otras profesiones humanas, habría que distinguir la del actor, que con un papel que no le compromete en sus actitudes personales de vida íntima, excepto en el propósito de representar a un personaje que le es ajeno, es una persona versátil: sólo pretende la representación ocasional de la tarea asignada, incluso casi con el deseo exclusivo de quedar él bien ante el público, es decir, del éxito, el aplauso y la satisfacción estética. El papel del profesor o del orador, que, aunque ofrecen algo más de su mundo interior, cultural o moral, por su propia naturaleza no les compromete en su totalidad, porque sus enseñanzas de realidades muy diversas suelen ser neutrales, sin implicarles en sus propósitos de vida personal. El predicador del Evangelio o heraldo de la Palabra de Dios, como ha de ser el obispo, aunque se pueda asemejar en sus enseñanzas al magisterio profesoral o a la función oratoria, está más cerca de la misión de los profetas en la historia de la salvación de todos los tiempos, pero con el acento de la sucesión apostólica que Cristo quiso para su Iglesia: habla no en nombre propio sino de Dios, por unas palabras que le han transformado a él mismo, porque son palabras de fe en el misterio de Cristo muerto y resucitado como Salvador del mundo; su persona pertenece al mundo de la Palabra: seducido, copado por ella, pone desde su interior, desde lo más profundo de su ser, algo que no le pertenece, para la salvación integral de todos los hombres. Es decir, tiene que ser en la Iglesia un testigo cualificado de Cristo resucitado.

Jesucristo dijo en el momento de dejar a los Apóstoles: "Recibiréis la virtud del Espíritu Santo, que descenderá sobre vosotros, y seréis mis testigos en Jerusalén y en toda Judea, en Samaria y hasta los confines del mundo" (Hech 1, 8). Hay que releer los Hechos de los Apóstoles para sentir toda la emoción de estas comunidades cristianas de los orígenes: la irradiación de su fe, esperanza y caridad, como fraternidades vivientes y unidas, virtudes con las cuales se hacían fermento para el mundo desde el testimonio de Cristo por sus vidas transformadas. El Vaticano II a este respecto ha insistido en dos conceptos fundamentales: el testimonio -de vida y de palabra- y el servicio (LG 34). Cristo es el primer servidor (cf. Mt 20, 28; Flp 2, 7) y el testigo por excelencia (cf. Ap 1, 5; Jn 1, 18). Es un testimonio que se traduce en una actitud práctica de servicio: querer el bien de todos los hombres procuran- 
do su inclusión en la Verdad trascendental (cf. Jn 17, 17), que libera y salva. La acción evangelizadora es anunciar a Cristo por el testimonio de vida y palabra (LG 35), mediante esta vida teologal y testimonial (LG 31), y de toda la comunidad: "todos en conjunto y cada cual en particular" (LG 38).

El alma del testimonio es esa confianza que produce una certeza viviente y personal que impulsa a proclamar algo de lo que se está interiormente seguro, aunque no se vea al Invisible con los ojos corporales, pero sí, de alguna manera con los del corazón (cf. Ef 1, 18; 1 Pe 8, 8). Un apóstol es el que guía a los demás hacia lo invisible. No es que él lo vea; es que lo cree, lo vive. Es el hombre de la Palabra, no porque se la apropie en exclusiva como si fuera su portavoz único, sino porque la ha recibido primero y se ha fiado: "Sé a quién me he confiado" ( 2 Tim 1, 12). Diríase que lo experimenta. Experiencia que procede de la adhesión viva y total a Cristo, que produce su Espíritu al morar en el fondo de su alma. Los Apóstoles tuvieron una elocuencia irresistible a partir de Pentecostés. Tenían la certidumbre viva de la permanencia del Espíritu que les asistía en la misión encomendada por Cristo, y daban testimonio de Él, que habiendo entregado su vida por nuestros pecados, había resucitado por nuestra justificación. Daban testimonio coherente e inquebrantable de y con la fuerza de Cristo resucitado. Por eso afirma San Pablo: "Si tus labios profesan que Jesús es el Señor y tu corazón cree que Dios le resucitó de entre los muertos, te salvarás" (Rm 10, 9). Creer y proclamar esta verdad central de la Buena Noticia de salvación: ¡Cristo resucitado! Por eso hay que ir más allá de una fe puramente intelectual, para llegar a esta experiencia profunda del corazón, a fin de poder ser heraldo o testigo de la Palabra, que ya tiene esa virtud salvadora para siempre y para todos los hombres en el señorío de Cristo glorificado.

"Así resulta claro que todas las actividades del obispo deben orientarse a proclamar el Evangelio, "que es una fuerza de Dios para la salvación de todo el que cree' $(\mathrm{Rm} 1,16)$. Su cometido esencial es ayudar al pueblo de Dios a que corresponda a la revelación con la obediencia de la fe (cf. Rm 1, 5) y abrace íntegramente la enseñanza de Cristo (...) El testimonio de vida es para el obispo como un nuevo título de autoridad, que se añade al título objetivo recibido en la consagración. A la autoridad se une el prestigio. Ambos son necesarios", dice esta exhortación (PG 32). Pero entendidas las cosas en sentido de la coherencia evangélica de las 
bienaventuranzas y del mandamiento nuevo del testimonio de Cristo mismo como siervo, para estar vigilantes frente a ese "prestigio" que parece prevalecer en la sociedad y acerca del cual nos previno el mismo Cristo, con el fin de poder ser sus seguidores en el camino hacia Jerusalén y participar en su misterio pascual. Se trata de advertirnos, en este caso, que no basta la potestad sagrada y jurídica, sino que es necesaria también la autoridad moral, que ayuda a madurar en la fe y hacer crecer a los demás en la vida cristiana, por la coherencia del mensajero en lo que les recomienda o enseña.

Porque toda persona con algún relieve social corre el riesgo de convertirse en personaje, es decir, de sofocar su espontaneidad por las normas que regulan su función, de sentirse inclinada a ocultar su rostro con la máscara del prestigio que hay que conservar, a cubrir la vida con el ropaje de su rango. Y así, a estas personas nunca se las ve vivir; se las ve mandar o actuar representando un papel, defendiendo un orden establecido. Afortunadamente, en la sociedad en que vivimos se reclama cada vez más la autenticidad de las personas, sobre todo por parte de las nuevas generaciones, que estiman por encima de otras cosas la cercanía y la sinceridad de sus posibles "maestros". Este es el "prestigio" evangélico, fundado en la humildad, la rectitud de intención, el servicio gratuito que se nos exige a todos, y a los que están en niveles altos, todavía más, porque Cristo, que es el Maestro y Señor por excelencia, se arrodilla a los pies de aquellos a los que quiere servir. El Papa, siguiendo la doctrina de San Pablo y citando a San Hilario de Poitiers, aclara: "por un lado, un ministro de vida irreprochable, si no es culto, conseguirá sólo ayudarse a sí mismo; por otro, un ministro culto pierde la autoridad que proviene de su cultura si su vida no es irreprensible". Cultura y vida, coherencia personal, la entrega de la persona desde su interior insobornable al servicio de la evangelización: es un arte difícil que sólo se aprende en docilidad al Espíritu y tratando de contemplar el rostro de Cristo y de los primeros Apóstoles, que fueron a la vez mártires también.

Los sociólogos, cuando se trata de la autoridad en una sociedad, hablan de la autoridad simbólica, aquella que en su transparencia y entrega al servicio de los valores y objetivos que representa en esta sociedad para sus miembros, ha de personificarlos para que éstos puedan creer en esos fines que propone; esta autoridad simbólica no puede permitirse ni reservas ni consideraciones a sus propios intereses. Por 
eso ha de tener el ingenio y el coraje, la esperanza y la decisión a la hora de aceptar y desempeñar este cargo. La autoridad ideológica es la que abarca el horizonte y no tiene respuestas inmediatas e individualizadas para todo sin la ayuda de los que se encuentran en esas situaciones concretas; por eso hace preguntas, escucha y dialoga sin olvidar que ha de ser testigo de esa verdad que manifiesta el ideal, a veces utópico, que propone. Autoridad interpersonal y comunitaria, que pretende desarrollar lo más posible los talentos o cualidades de los demás, suscitando su colaboración, de ser posible de una manera gustosa y afectiva, como en familia o fraternidad, sanando, consolando, animando, sencillamente, como Cristo hacía con los suyos, incluso con esa longanimidad y paciencia que muestra en sus relaciones con todos, aunque cuando era necesario desenmascarase las intenciones torcidas de algunos. Autoridad administrativa o esfuerzo para organizarse, con la formación de los colaboradores, las orientaciones necesarias y los cuidados para que la "administración" funcione bien según el fin pretendido, atendiendo a los objetivos y a sus resultados, pero todavía mejor, a las actitudes auténticas.

Es, en todo caso, como recapitulación de lo que todo esto pueda servir para la función del obispo como "maestro de la fe y heraldo de la Palabra", la autoridad pastoral del que entrega su vida a semejanza de Cristo, Buen Pastor (cf. Jn 10, 1-16).

+José Delicado, Arzobispo emérito de Valladolid 